\title{
Calpastatin Exon 1B-Derived Peptide, a Selective Inhibitor of Calpain: Enhancing Cell Permeability by Conjugation with Penetratin
}

\author{
Shirley Gil-Parrado1,2,a, Irmgard Assfalg- \\ Machleidt',2,a , Ferdinando Fiorino ${ }^{3}$, Dominga \\ Deluca $^{3}$, Dietmar Pfeiler ${ }^{1,2, b}$, Norbert \\ Schaschke ${ }^{3}$, Luis Moroder ${ }^{3}$ and Werner \\ Machleidt',* \\ ${ }^{1}$ Abteilung für Klinische Chemie und Klinische \\ Biochemie, Chirurgische Klinik Innenstadt, Klinikum der \\ Ludwig-Maximilians-Universität, Nußbaumstr. 20, \\ D-80336 München, Germany \\ ${ }^{2}$ Adolf-Butenandt-Institut für Physiologische Chemie, \\ Physikalische Biochemie und Zellbiologie der Ludwig- \\ Maximilians-Universität, Schillerstr. 42, \\ D-80336 München, Germany \\ ${ }^{3}$ Max-Planck-Institut für Biochemie, Am Klopferspitz \\ 18a, D-82152 Martinsried, Germany \\ ${ }^{*}$ Corresponding author
}

The ubiquitous calpains, $\mu$ - and $\mathrm{m}$-calpain, have been implicated in essential physiological processes and various pathologies. Cell-permeable specific inhibitors are important tools to elucidate the roles of calpains in cultivated cells and animal models. The synthetic $\mathrm{N}$-acetylated 27-mer peptide derived from exon $B$ of the inhibitory domain 1 of human calpastatin (CP1B) is unique as a potent and highly selective reversible calpain inhibitor, but is poorly cell-permeant. By addition of $\mathrm{N}$-terminal cysteine residues we have generated a disulfide-conjugated CP1B with the cell-penetrating 16-mer peptide penetratin derived from the third helix of the Antennapedia homeodomain protein. The inhibitory potency and selectivity of CP1B for calpain versus cathepsin B and L, caspase 3 and the proteasome was not affected by the conjugation with penetratin. The conjugate was shown to efficiently penetrate into living LCLC $103 \mathrm{H}$ cells, since it prevents ionomycin-induced calpain activation at $\mathbf{2 0 0}$-fold lower concentration than the non-conjugated inhibitor and is able to reduce calpain-triggered apoptosis of these cells. Penetratinconjugated CP1B seems to be a promising alternative to the widely used cell-permeable peptide aldehydes

\footnotetext{
a These authors contributed equally to this work.

b Present address: Lehrstuhl für Anorganische und Analytische Chemie der Technischen Universität München, Lichtenbergstr. 4, D-85747 Garching, Germany
}

(e.g. calpain inhibitor I) which inhibit the lysosomal cathepsins and partially the proteasome as well or even better than the calpains.

Key words: Apoptosis/Calpain/Calpain inhibitors /

Calpastatin/lonomycin/Penetratin.

\section{Introduction}

The ubiquitous calpains, $\mu$ - and $\mathrm{m}$-calpain ( $\mu$-and $\mathrm{mCP}$ ), are cytosolic calcium-dependent cysteine proteases that are present in almost all mammalian cells (see Sorimachi and Suzuki, 2001, for a recent review). Usually the calpains coexist with their specific endogenous protein inhibitor, calpastatin, which binds reversibly to the $\mathrm{Ca}^{2+}$ activated enzymes and inhibits them selectively and efficiently (Takano et al., 1995).

Although results with transgenic (knockout) mice deficient in calpain small subunit gene (Arthur et al., 2000) point to essential cellular functions of the calpains, and a great number of putative calpain substrates have been demonstrated in vitro, not yet many calpain-dependent processes have been definitely identified. The ubiquitous calpains seem to be involved in signaling pathways (Sato and Kawashima, 2001), controlling cell proliferation (Carragher et al., 2002), differentiation (Yajima and Kawashima, 2002) and motility (Glading et al., 2002) as well as cell death (Squier et al., 1999; Wang, 2000; Lu et al., 2002; Gil-Parrado et al., 2002). Proteolysis by undue activity of ubiquitous calpains has been implicated in various pathologies, such as neuronal and myocardial ischemia/reperfusion, inflammation or neurodegenerative disorders (reviewed in Vanderklish and Bahr, 2000; Huang and Wang, 2001). Therefore, calpains constitute potential therapeutic targets in diseases.

A great number of conclusions concerning the role of calpains in physiological or pathological processes is based on the effects of calpain inhibitors in cultured cells or animal models. Manipulation of the cellular level of calpastatin by overexpression or antisense techniques have been used in cell culture studies (e.g. Hiwasa et al., 2002), but the large majority of experiments have been performed with exogenous synthetic calpain inhibitors that are sufficiently cell-permeable to reach their intracellular targets.

The search for cell-permeable calpain inhibitors has been an ongoing process following the discovery of the enzyme over 30 years ago (Donkor, 2000). Nonselective calpain inhibitors such as EDTA and EGTA $\left(\mathrm{Ca}^{2+}\right.$-chela- 
tors) were followed by more potent and/or more selective calpain inhibitors isolated from natural sources or synthesized (reviewed in Wang and Yuen, 1997; Donkor, 2000). Most of them react covalently with the catalytic cysteine residue of calpain, but, with few exceptions, their selectivity for the calpains is low. For instance, various peptide aldehydes that have been extensively used for in vivo calpain inhibition (e.g. Ac-Leu-Leu-Nle-CHO, here abbreviated as AcLLNal, 'calpain inhibitor l'), are potent inhibitors also of the lysosomal cathepsins $L$ and $B$ (Sasaki et al., 1990) and of the proteasome (Stein, et al., 1996). Moreover, the calpain inhibitor calpeptin (Z-Leu-Nle$\mathrm{CHO}$ ) was shown to inhibit protein tyrosine phosphatases as well (Schoenwaelder and Burridge, 1999). During the last decade much effort has been spent in the development of peptidic, peptidomimetic or non-peptide calpain inhibitors of improved selectivity and good bioavailability, but few of these inhibitors have been completely characterized in terms of selectivity or have been used extensively as tools in basic research (Donkor, 2000; Hernandez and Roush, 2002).

The $\alpha$-mercaptoacrylic acid derivative PD150606, a non-peptide cell-permeable calpain inhibitor that binds to the calmodulin-like domains of the large and the small subunit and inhibits calpain uncompetitively, has been considered to be selective for calpain (Wang et al., 1996), but has recently been shown to interfere with excitoxicity-dependent motor neuron death purely mediated through $\mathrm{Ca}^{2+}$-permeable AMPA receptors despite other calmodulin and calpain inhibitors were not effective (Van Den Bosch et al., 2002).

The most selective synthetic inhibitor of calpains that is presently available is a $\mathrm{N}$-acetylated and $\mathrm{C}$-amidated 27-mer peptide derived from exon $\mathrm{B}$ of the inhibitory domain 1 of human calpastatin (CP1B; Maki et al., 1989) which binds reversibly to the catalytic subunit of $\mu$ - and m-calpain (Maki et al., 1988). This peptide, also called 'acetyl calpastatin 27-peptide' (AC27P; Gil-Parrado et al., 2002), does not inhibit papain or trypsin (Maki et al., 1989) and is considered to be highly selective for the ubiquitous calpains, although so far quantitative data on its inhibitory specificity have not been reported. CP1B, which is commercially available, has successfully been used by several investigators for inhibition of calpain activity in living cells (Eto et al., 1995; Yamazaki et al., 1997a,b; Kusakawa et al., 2000; Blomgren et al., 2001; Shiraishi et al., 2001; Gil-Parrado et al., 2002). Using a rhodamine-labeled peptide, uptake of CP1B into cells was confirmed (Eto et al., 1995). However, high concentrations were needed by all investigators to achieve intracellular effects, indicating that the 27-mer is poorly cellpermeable.

Here we report quantitative in vitro inhibition data confirming the presumed high selectivity of CP1B for $\mu$-calpain over other typical intracellular proteases, such as cathepsin $L$ and $B$, caspase 3 and the proteasome. Cell permeability of this highly selective calpain inhibitor was substantially increased by conjugation with the cell-penetrating peptide penetratin, a 16-mer peptide derived from the third helix of the homeodomain of the Antennapedia protein (Derossi et al., 1998) which has been widely used for intracellular delivery of peptides and oligonucleotides (Fischer et al., 2001). The resulting new calpain inhibitor, penetratin-calpastatin peptide 1B (PCP1B), was

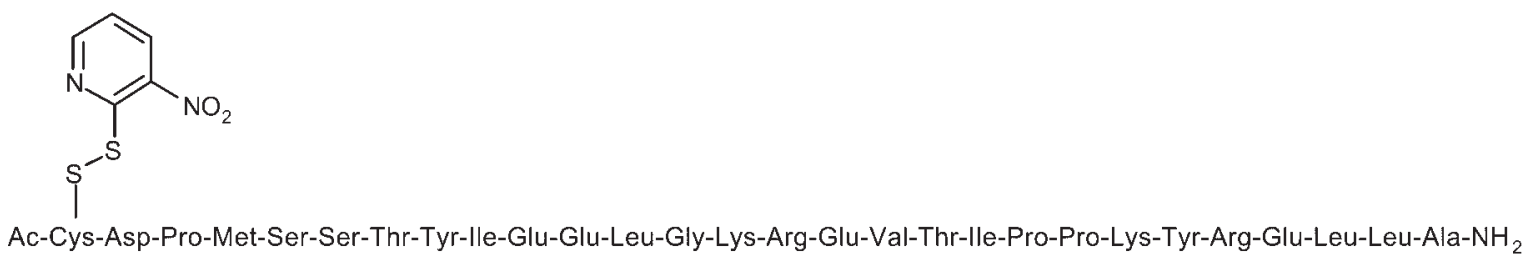

1

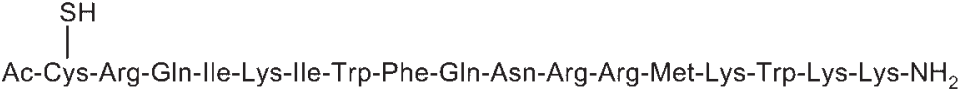

2<smiles>O=C(NOC(=O)c1ccccc1)Oc1ccc[nH]c1=S</smiles>

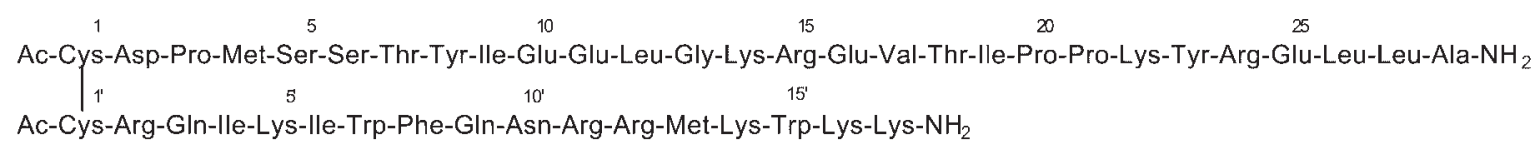

Fig. 1 Structure and Synthesis of the Calpastatin Exon 1B-Derived Peptide-Penetratin Conjugate (PCP1B). 
able to inhibit ionomycin-induced calpain activation in living cells at submicromolar concentrations and to prevent calpain-triggered apoptosis. These features constitute a promising substitute for widely used cell-permeable calpain inhibitors of low selectivity.

\section{Results}

\section{Synthesis of Penetratin-Conjugated Calpastatin Exon 1B-Derived Peptide (PCP1B)}

The CP1B-penetratin conjugate $\mathbf{3}$ was synthesized as shown in Figure 1. To crossbridge the calpastatin-derived peptide with penetratin via a disulfide bridge, both peptides were appropriately modified by $\mathrm{N}$-terminal elongation with $\mathrm{N}$-acetyl cysteine. Selective formation of the disulfide bond was achieved by reacting S-Npys-activated peptide 1 with the free thiol of modified penetratin 2 (Bernatowicz et al., 1986). The resulting conjugate 3, penetratin-calpastin peptide 1B (PCP1B), was fully characterized by RP-HPLC, quantitative amino acid analysis, and ESI-MS (data not shown). The solubility of CP1B was substantially increased by the conjugation with the basic penetratin peptide.

\section{CP1B and PCP1B Are Potent and Selective Calpain Inhibitors}

The inhibitory profile of CP1B against four typical cellular cysteine proteases and the human 205 proteasome demonstrates that the calpastatin-derived peptide is a very potent $\left(K_{\mathrm{i}}=0.2 \mathrm{nM}\right)$ and highly selective inhibitor of calpain (Table 1). Whereas the activity of cathepsin B, caspase 3 and the chymotryptic activity of the 20S proteasome are virtually not affected, the selectivity for $\mu$ calpain over cathepsin $L$ is still 30000 -fold. Inhibition of cathepsin L by CP1B is comparable to that obtained with a 'scrambled' peptide of the same amino acid composition (Eto et al., 1995). In contrast, the cell-permeable pep- tidyl aldehyde Ac-LLNal (calpain inhibitor I) has about the same affinity for cathepsin B and even 160-fold higher affinity for cathepsin $L$ when compared with $\mu$-calpain (Table 1).

The high inhibitory potency of CP1B for calpain remains essentially unchanged after conjugation with penetratin, whereas the $\mathrm{N}$-acetylated Cys-penetratin vector (AcP) alone does not inhibit $\mu$-calpain. $K_{\mathrm{i}}$ values of PCP1B for the two cathepsins are still in the micromolar range, and a similar micromolar $K_{\mathrm{i}}$ was determined with AcP itself. Inhibition of cathepsin $L$ and $B$ by AcP and $\mathrm{PCP} 1 \mathrm{~B}$ was temporary, indicating that the free and the conjugated penetratin peptide is slowly degraded as a substrate. This was confirmed by the detection of cleavage products after incubation with higher concentrations of cathepsin $L(\geq 0.25 \mathrm{~nm})$. PCP1B was cleaved by cathepsin L in the penetratin portion between GIn9' and Asn10', and AcP additionally between Arg11' and Arg12' (see sequences in Figure 1). In contrast, in PCP1B no cleavages were observed with $\mu$-calpain, even with 100fold higher enzyme concentrations than used in the inhibition assays. From this we expect that the penetratin moiety may be proteolytically degraded by intracellular proteases after cellular uptake, as has been suggested (Waizenegger et al., 2002). Penetratin contains several basic residues which are preferred cleavage sites of proteases, and a half life of $1 \mathrm{~h}$ has been estimated in mammalian reticulocytes (Lindgren et al., 2000a).

\section{PCP1B Is a Cell-Permeable Calpain Inhibitor}

LCLC $103 \mathrm{H}$ cells, a cell line derived from a human large cell lung carcinoma (Bepler et al., 1988), were used for cell permeation studies, because we had shown previously that ionomycin-induced calpain activity in these cells is effectively inhibited by preincubation with AC27P (CP1B) (Gil-Parrado et al., 2002). Here we compared the inhibitory effect of PCP1B and CP1B on the intracellular calpains. lonomycin-induced hydrolysis of the cell-permeable fluorogenic substrate Suc-LLVY-amc was meas-

Table 1 Selectivity of Calpain Inhibition by Calpastatin-Derived Peptide 1B (CP1B) and Its Penetratin Conjugate (PCP1B).

\begin{tabular}{|c|c|c|c|c|c|}
\hline \multirow[t]{2}{*}{ Inhibitor } & \multicolumn{5}{|c|}{$K_{\mathrm{i}}(\mu \mathrm{M})^{\mathrm{a}}$} \\
\hline & $\mu$-Calpain & Cathepsin L & Cathepsin B & Proteasome ${ }^{b}$ & Caspase 3 \\
\hline CP1B & 0.0002 & 6 & $\geq 500$ & $\geq 200$ & $\geq 500$ \\
\hline CP1B scrambled" & 6 & 6 & $\geq 500$ & $\geq 200$ & $\geq 200$ \\
\hline PCP1B & 0.0005 & $0.8^{e}$ & $12^{\mathrm{e}}$ & $\geq 200$ & $\geq 200$ \\
\hline $\mathrm{AcPc}$ & $\geq 50$ & $1.0^{\mathrm{e}}$ & $\geq 130^{\mathrm{e}}$ & $\geq 200$ & $\geq 200$ \\
\hline AcLLNalc & $0.003^{d}$ & 0.00003 & $0.002^{\mathrm{d}}$ & $0.5^{\mathrm{e}}$ & $\geq 9000$ \\
\hline
\end{tabular}

aMean of 5-10 experiments with individual inhibitor concentrations (S.D. $<10 \%$ ). $\geq$ values are 10 -fold the highest used inhibitor concentration that resulted in less than $10 \%$ inhibition.

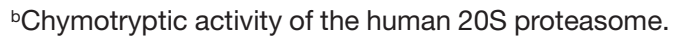

'Data obtained with 'scrambled' CP1B (see 'Results') and AcP (N-acetyl-Cys-penetratin) are included as controls, data with AcLLNal ('calpain inhibitor l') for comparison.

'Data taken from Schaschke et al. (1996).

eTemporary inhibition (see text for explanation). 


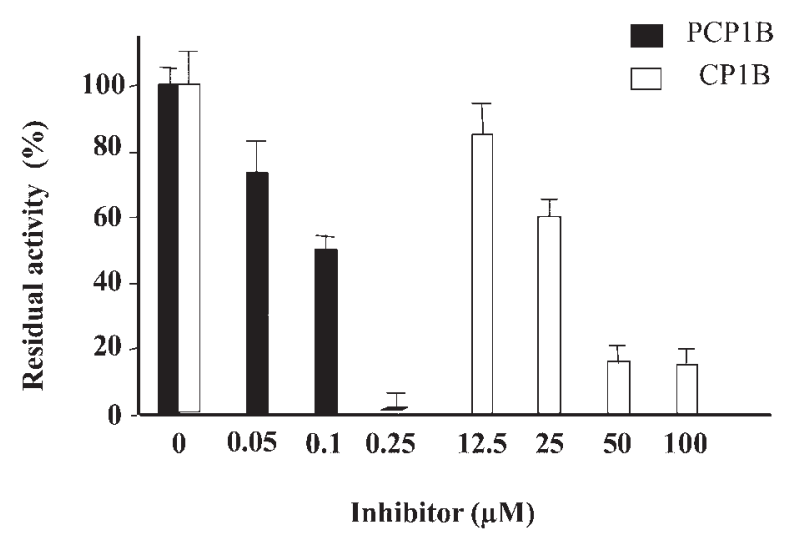

Fig. 2 Inhibition of Calpain Activity and Calpain-Mediated Apoptosis in Living LCLC 103H Cells by Penetratin-Linked Calpastatin Exon 1B-Derived Peptide (PCP1B).

Inhibition of ionomycin-induced Suc-LLVY-amc hydrolyzing activity. Residual ionomycin-induced Suc-LLVY-amc hydrolyzing activity (\%) measured in cells after $30 \mathrm{~min}$ of incubation with the fluorogenic substrate $\left(37^{\circ} \mathrm{C}\right)$ following pre-incubation with $\mathrm{CP} 1 \mathrm{~B}$ or PCP1B at the indicated concentrations. $100 \%$ represents the Suc-LLVY-amc hydrolyzing activity induced by addition of $2 \mu \mathrm{M}$ ionomycin in the absence of inhibitors. All experiments were performed in triplicate; SD are indicated by bars; all depicted data are significantly different $(p<0.01)$ from the controls $(0$, ionomycin-treated cells in the absence of inhibitors).

ured in non-treated control cells (100\%) and after preincubation with increasing concentrations of CP1B and PCP1B, respectively (Figure 2). Whereas ionomycin-induced activity was reduced to $15 \%$ by $50 \mu \mathrm{M}$ CP1B (a concentration widely used in the cell culture models cited in the Introduction section), a concentration of PCP1B as low as $0.25 \mu \mathrm{m}$ yielded almost complete inhibition. Preincubation of the cells with the penetratin vector (AcP) itself had no significant effect (data not shown). These data clearly demonstrate a substantial increase of cell-permeability due to the conjugation of $\mathrm{CP} 1 \mathrm{~B}$ with penetratin. The penetratin-conjugated peptide is able to penetrate into LCLC $103 \mathrm{H}$ cells where it prevents ionomycin-induced calpain activation at roughly 200 -fold lower concentrations (in the surrounding medium) than the nonconjugated inhibitor.

\section{PCP1B Protects LCLC 103H Cells against Ionomycin-Induced Apoptosis}

We have recently shown that ionomycin-activated calpain triggers apoptosis in LCLC $103 \mathrm{H}$ cells and that apoptosis was prevented by preincubation of these cells with 50 4M CP1B (AC27P; Gil-Parrado et al., 2002). Here we used this model to compare the effects of $\mathrm{CP} 1 \mathrm{~B}$ and $\mathrm{PCP} 1 \mathrm{~B}$ on the percentage of apoptotic cells, estimated by FACS analysis for phosphatidyl serine externalization (annexin $\mathrm{V}$ binding) and propidium iodide uptake $3 \mathrm{~h}$ after incubation with $2 \mu \mathrm{M}$ ionomycin (Figure 3). Whereas apoptotic cells were reduced to roughly $25 \%$ by $50 \mu \mathrm{M}$ $\mathrm{CP} 1 \mathrm{~B}$, the same reduction was achieved by only $10 \mu \mathrm{M}$

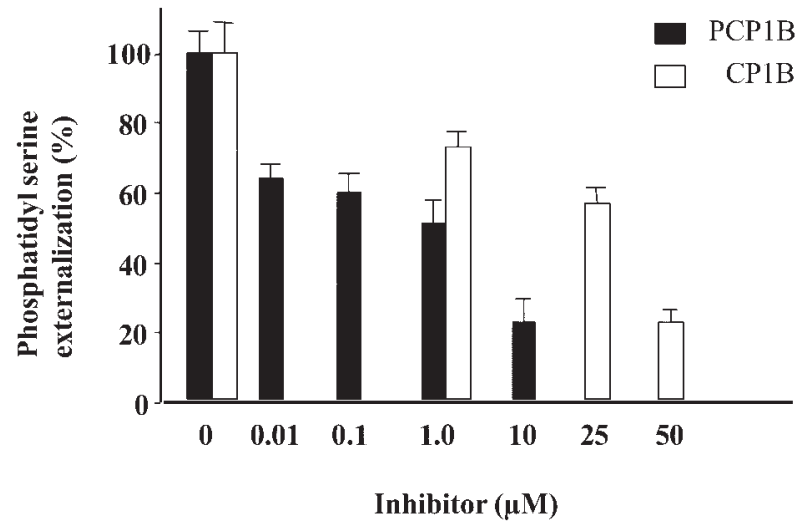

Fig. 3 Inhibition of lonomycin-Induced Apoptosis by Free and Penetratin-Linked CP1B.

To cells treated with the indicated inhibitors, annexin V-fluorescein and propidium iodide were added before counting and sorting by FACS as described in Materials and Methods. Phosphatidylserine externalization (\%) represents the percentage of cells positive for phosphatidylserine externalization and negative for propidium iodide uptake after addition of $2 \mu \mathrm{m}$ ionomycin for $3 \mathrm{~h}$ at $37^{\circ} \mathrm{C}$, related to the total amount of cells. All experiments were performed in triplicate; SD are indicated by bars; all depicted data are significantly different $(p<0.01)$ from the controls ( 0 , ionomycin-treated cells in the absence of inhibitors).

PCP1B. The penetratin vector itself had no significant effect on the number of apoptotic cells (data not shown).

\section{Discussion}

As long as the three-dimensional structure of a calciumactived calpain or a substrate/inhibitor complex of calpain is not available, structure-based modeling of synthetic calpain inhibitors will be not feasible. It remains to be established whether the recently published structure of a $\mathrm{Ca}^{2+}$-activated 'minicalpain' comprising the catalytic domain II plus domain I (Moldoveanu et al. , 2002) will enable the design of more selective inhibitors, since this very papain-like fragment displays less than $5 \%$ of the specific enzymatic activity of complete calpain. It seems probable that other domains of the calpain molecule participate in substrate recognition and are responsible for the highly selective binding of protein substrates and of the endogenous protein inhibitor calpastatin. This is underscored by the results of structure-activity relationship (SAR) studies (Donkor, 2000) indicating that affinity and selectivity of calpain for small peptide substrates and inhibitors are low when compared to other cysteine proteases.

The shortest peptide binding to calpain with outstanding affinity and selectivity is the 27-mer derived from exon $1 \mathrm{~B}$ of calpastatin domain 1 (CP1B). The mechanism of inhibition of this peptide and its binding site on calpain are unknown, but it has been shown that $\mathrm{N}$-terminal or $\mathrm{C}$-terminal truncation by a few residues reduces its inhibitory 
potency drastically (Uemori et al., 1990). A similar synthetic 24-mer peptide, derived from a consensus sequence of all four inhibitory domains of porcine calpastatin has been described (Croall and McGrody, 1994). Maki et al., who introduced CP1B (Maki et al., 1989), reported that it does not inhibit either papain or trypsin. Here we confirmed and extended these findings by quantitative data on the inhibition of selected intracellular proteases. Although only few typical cellular proteases were considered, our data suggest that CP1B is a potent and highly selective calpain inhibitor.

As shown previously (Kawasaki et al., 1989), inhibition of calpain by CP1B is reversible and competitive with substrates. Considering a $K_{\mathrm{i}}$ value of $0.2 \mathrm{~nm}$ as determined in this work, an intracellular concentration of about $20 \mathrm{nM}$ CP1B would be required for $99 \%$ inhibition of $\mu$ calpain. However, even $100 \mu \mathrm{M}$ CP1B in the surrounding medium was not sufficient to completely inhibit calpain activity in living cells. This discrepancy is obviously due to the poor cell permeability of CP1B that has been observed in previous cell culture studies (see references cited in 'Introduction') and apparently precludes this selective calpain inhibitor from use in isolated organ perfusion and animal models as well as from potential therapeutic application.

The most promising approach to increase cell permeability of a large hydrophilic peptide like CP1B seemed to conjugate it with a cell-penetrating peptide vector (reviewed in Lindgren et al., 2000b; Fischer et al., 2001). We decided in favor of penetratin, a 16-mer peptide derived from the third helix of the homeodomain of the Antennapedia protein (Derossi et al., 1998). This peptide penetrates membranes through an energy-independent mechanism that is not precisely known and translocates conjugated cargo peptides or even proteins into the cytoplasm and the cell nucleus. Recently, we have used the C-terminal heptapeptide segment of penetratin as a vector for intracellular delivery of an epoxysuccinyl peptidederived selective cathepsin B inhibitor (Schaschke et al., 2002). Here, as in most previously reported applications of penetratin, we disulfide-linked full-length Cys-penetratin to Cys-CP1B. The disulfide-linked cargo is supposed to be rapidly released in the reductive intracellular milieu (Hällbrink et al., 2001).

It has been shown recently by fluorescence correlation spectroscopy that penetratin-conjugated fluorophores are imported into living cells even at nanomolar concentrations (Waizenegger et al., 2002). By fluorescence microscopy we detected uptake of biotinylated penetratin into LCLC $103 \mathrm{H}$ cells at concentrations above $100 \mathrm{~nm}$ (data not shown). Accordingly, our penetratin-CP1B conjugate effected complete inhibition of ionomycin-induced intracellular calpain activity at concentrations in the nanomolar range (see Figure 2), close to the concentration required for complete inhibition of isolated $\mu$-calpain in vitro (see above). The high selectivity for calpain over the cathepsins $L$ and $B$, caspase 3 and the 20 s proteasome remained essentially unchanged after conjugation with penetratin (see Table 1). Therefore, PCP1B should allow effective and selective calpain inhibition in cell culture models, isolated organs or whole animals at concentrations in the submicromolar or low micromolar range.

Surprisingly, the protective effect of PCP1B on calpain-induced apoptosis of LCLC $103 \mathrm{H}$ cells (Figure 3) was much less pronounced than was expected from inhibition of intracellular calpain activity (Figure 2). On the basis of available data we cannot satisfactorily explain this discrepance. However, phosphatidyl serine (PS) externalization, the mechanism of which is not fully understood (Naito et al., 1997), is a complex process at the end of the intrinsic apoptotic pathway triggered by calpain (Gil-Parrado et al., 2002) and may not strictly correlate with intracellular calpain activity determined by cleavage of a cell-permeable peptide substrate. More than $25 \%$ of ionomycin-induced PS externalization were inhibited neither by $10 \mu \mathrm{M}$ PCB1B nor by $50 \mu \mathrm{M}$ CP1B and seem to be not calpain-dependent (Figure 3). This portion should include cells that become apoptotic in the absence of ionomycin (up to $35 \%$ in previous studies; see Figure $3 \mathrm{~A}$ in Gil-Parrado et al., 2002).

A related approach using a different cell-penetrating peptide, the signal sequence of Kaposi's fibroblast growth factor (residues 7-22), peptide bond-linked to the consensus sequence of the four inhibitory domains of porcine calpastatin, has previously been reported for calpain inhibition in platelets (Croce et al., 1999). This conjugate, called 'calpastat', displayed an $\mathrm{IC}_{50}$ of $70 \mathrm{~nm}$ for inhibition of isolated $\mu$-calpain, and $\mathrm{IC}_{50}$ values between 20 and $50 \mu \mathrm{m}$ for biological effects in platelets. The use of a consensus sequence (Croall and McGrody, 1994) instead of CP1B seems to be responsible for the 350-fold lower inhibitory potency of 'calpastat' when compared to PCP1B, but biological effects have been reported with similar concentrations (Croce et al., 1999).

Due to the lack of selective calpain inhibitors that are readily cell-permeant, even very recent studies addressing the physio(patho)logical relevance of calpain have been performed using inhibitors of low selectivity or poor cell permeability (e.g. Bordone and Campbell, 2002; Rutledge and Whiteheart, 2002; Chen et al., 2002, among many others). The new selective and cell-permeable inhibitor described here may help to confirm or question results obtained with less specific inhibitors and to discriminate between the effects of calpain and other cellular proteases (Yamashima, 2000). The inherent drawback of a rather complicated synthesis of this long peptide should be accepted as long as equally cell-permeable and specific calpain inhibitors of smaller size are not available.

\section{Materials and Methods}

\section{Materials}

$\mu$-Calpain was isolated from human erythrocytes (GabrijelcicGeiger et al., 2001). Human $20 S$ proteasome was obtained from Affiniti Research Products (Mamhead, Exeter, UK). Cathepsins L 
and $B$, active recombinant caspase 3 , the scrambled calpastatin peptide and calpain inhibitor I (Ac-LLNal) were purchased from Calbiochem (Bad Soden, Germany). Calpastatin peptide (CP1B) was from Sigma or Calbiochem. Substrates Suc-LY-amc, SucLLVY-amc, Z-FR-amc and Ac-DEVD-amc were from Bachem (Heidelberg, Germany), ionomycin from Calbiochem, avidinFITC from Zymed Laboratories (South San Francisco, CA, USA). All other reagents were of the highest purity commercially available. The LCLC $103 \mathrm{H}$ cell line (ACC 384) was supplied by DSMZ-GmbH (Braunschweig, Germany).

\section{Peptide Synthesis and Purification}

Compound 1 (Figure 1), calpastatin exon 1B peptide functionalized at its $\mathrm{N}$-terminus with a S-Npys-activated $\mathrm{N}$-acetylated cysteine residue, was initially custom synthesized by the Microchemical Facility of Emory University, Winship Cancer Center (Atlanta, GA, USA) and later synthesized in our laboratory by the method described below for Compound 2. Compound 2 (Figure 1), penetratin $\mathrm{N}$-terminally elongated with a $\mathrm{N}$-acetylated cysteine residue, was synthesized on a Applied Biosystems peptide synthesizer (model 431A) by standard Fmoc/tBu chemistry on Rink amide (MBHA) resin using double coupling of Fmoc-amino acids/HBTU/HOBt/DIEA (1:1:1:2; 4 equiv.). N-terminal acetylation was carried out with acetic anhydride/DIEA (1:1.5; 10 equiv.) and final cleavage/deprotection was performed with $95 \%$ aq TFA/triisopropylsilane (98.5:1.5) yielding StBu-protected 2 which was purified by RP-HPLC on Nucleosil C18 using a linear gradient form $18 \%$ B to $45 \%$ B within 60 min (eluent $A$ : $0.1 \%$ aq TFA; eluent B: $0.08 \%$ TFA in acetonitrile). The resulting product was deprotected by treatment with tri-n-butylphosphine (5 equiv.) in 95\% aq TFE. Conjugate 3 was synthesized by adding under an argon atmosphere peptide 2 (1 equiv.) dissolved in $50 \mathrm{~mm} \mathrm{NH}_{4} \mathrm{OAc}$-buffer ( $\mathrm{pH} 5$, degassed and saturated with argon) slowly to a solution of $\mathbf{1}$ (1 equiv.) in the same buffer. After purification by gel chromatography on Fractogel HW $40 \mathrm{~S}$ using $1 \%$ aq $\mathrm{AcOH}$ as eluent, 3 was fully characterized by RPHPLC, quantitative amino acid analysis, and ESI-MS.

\section{Inhibition Assays and $\boldsymbol{K}_{\mathrm{i}}$ Determination}

Inhibition of $\mu$-calpain $\left(0.5-1 \mathrm{~nm}\right.$ ) was measured at $12^{\circ} \mathrm{C}$ (to slow down inactivation by autolysis) with the fluorogenic substrate Suc-LY-amc (250 $\mu \mathrm{m})$ in $50 \mathrm{~mm}$ Tris/ $\mathrm{HCl}, \mathrm{pH} 7.5,100 \mathrm{~mm} \mathrm{NaCl}$, $0.015 \%$ Brij-35 (calpain buffer), $150-200 \mu \mathrm{M} \mathrm{CaCl}, 1$ mM dithiothreitol (DTT). Cathepsin $\mathrm{L}(0.25 \mathrm{~nm})$ was assayed at $25^{\circ} \mathrm{C}$, pH 5.5 with $25 \mu \mathrm{M}$ Suc-LY-amc and cathepsin B $(25 \mathrm{pM})$ at $30^{\circ} \mathrm{C}$ with Z-FR-amc $(10 \mu \mathrm{M})$ in $0.25 \mathrm{~mm}$ sodium acetate, pH 5.5, $2 \mathrm{~mm}$ EDTA, $0.015 \%$ Brij-35. The chymotryptic activity of the human $20 \mathrm{~S}$ proteasome $(2 \mathrm{nM})$ was measured at $30^{\circ} \mathrm{C}$ with Suc-LLVYamc $(10 \mu \mathrm{m})$ in $50 \mathrm{~mm}$ Tris/ $\mathrm{HCl}, \mathrm{pH} 7.5,100 \mathrm{~mm} \mathrm{NaCl}, 0.5 \mathrm{~mm}$ EDTA, $0.025 \%$ SDS and caspase 3 activity at $25^{\circ} \mathrm{C}$ with AcDEVD-amc ( $5 \mu \mathrm{m})$ in $50 \mathrm{~mm}$ HEPES, pH 7.2, $100 \mathrm{~mm} \mathrm{NaCl}, 1 \mathrm{~mm}$ EDTA, $10 \%$ sucrose, $0.1 \%$ CHAPS and $10 \mathrm{~mm}$ DTT. Continuous assays were performed recording fluorescence (excitation $380 \mathrm{~nm}$, emission $460 \mathrm{~nm}$ ) essentially as described in Machleidt et al. (1993). After preactivation of the enzymes with DTT (exept the proteasome) in the presence of substrate and of $\mathrm{CaCl}_{2}(\mu$ calpain), about 5-10 different inhibitor concentrations, dissolved and prediluted in calpain buffer (or DMSO for AcLLNal), were added ( $\max .1 \%$ of the total test volume), and the reaction was followed until equilibrium. $K_{\mathrm{i}}$ values for the inhibition of $\mu$ calpain by the free and the penetratin-conjugated calpastatin peptide were obtained from presteady-state kinetics, fitting the progress data by nonlinear regression analysis to the integrated equation of Morrison (Morrison, 1982). From the rate constants $k_{\text {on }}$ and $k_{\text {off }}$ the $K_{\mathrm{i}}$-values were calculated as $K_{\mathrm{i}}=k_{\text {off }} / k_{\text {on }}$. All other inhibition constants were calculated from the initial and steady state rates using the equation for classical inhibition. $K_{\mathrm{i}}$ values were corrected for competition with the substrates. In cases of less than $10 \%$ inhibition, the $K_{\mathrm{i}}$-value was assumed to be at least 10 -fold the highest used inhibitor concentration.

\section{Cell Culture}

For routine cell culture, RPMI 1640 medium (Gibco-BRL) was supplemented with $10 \%$ fetal calf sera (Sigma) and 0.6\% L-glutamine (Gibco-BRL). Cells were maintained at $37^{\circ} \mathrm{C}$ in a humidified $5 \% \mathrm{CO}_{2}$ atmosphere. For inhibition experiments, the cells were maintained in serum-free HEPES-RPMI 1640 (Gibco-BRL). When being subcultured, cells were lifted using trypsin-EDTA solution (Gibco-BRL).

\section{Protease Activity and Inhibition Assay in Living Cells}

Suc-LLVY-amc hydrolyzing activity was determined by measuring hydrolysis of the peptidyl 7-amino bond of this fluorogenic substrate in LCLC $103 \mathrm{H}$ cells, plated on 24-well plates $\left(10^{5}\right.$ cells/well), in Hepes-buffered serum-free growth medium. Cells were pre-incubated with Suc-LLVY-amc $(160 \mu \mathrm{m})$ for $1 \mathrm{~h}$ at $37^{\circ} \mathrm{C}$ in a humidified $5 \% \mathrm{CO}_{2}$ incubator. Substrate hydrolysis was monitored using a fluorescence reading system (Fluoroskan ascent) with filter settings of $355 \pm 20 \mathrm{~nm}$ for excitation and $460 \pm 20 \mathrm{~nm}$ for emission. Prior to addition of $2 \mu \mathrm{m}$ ionomycin, the basal fluorescence, $F_{0}$, was recorded. Fluorescence readings, $F_{t}$, were collected every $5 \mathrm{~min}$ up to $120 \mathrm{~min}$ at $37^{\circ} \mathrm{C}$. Subsequently, plates were removed from the scanner, and incubated with lysis buffer ( $50 \mathrm{~mm}$ Hepes/KOH, $150 \mathrm{~mm} \mathrm{NaCl}, 1 \% \mathrm{NP}$ 40, pH 7.4) for $2 \mathrm{~h}$ at room temperature for protein concentration measurements. As there were no statistically significant differences in protein content between the wells, ionomycin-dependent proteolytic activity was expressed in arbitrary units and calculated as the linear slope $\Delta \mathrm{F}=\left(\mathrm{F}_{\mathrm{t}}-\mathrm{F}_{\mathrm{o}}\right) /\left(\mathrm{t}-\mathrm{t}_{\mathrm{o}}\right)$.

Inhibition of ionomycin-induced Suc-LLVY-amc hydrolyzing activity was measured after preincubation of the cells for $1 \mathrm{~h}$ at $37^{\circ} \mathrm{C}$ with the inhibitors $\mathrm{CP} 1 \mathrm{~B}$ and $\mathrm{PCP} 1 \mathrm{~B}$ dissolved in calpain buffer and diluted in Hepes-buffered serum-free growth medium at the indicated concentrations (see Figure 2) before addition of substrate. Note that these inhibitor concentrations were chosen taking into account prior results (Gil-Parrado et al., 2002) and the maintenance of cell viability. The residual activity (\%) was expressed as $\left[\left(\Delta \mathrm{F}-\Delta \mathrm{F}_{\text {inh }}\right) / \Delta \mathrm{F}\right] \times 100$, where $\Delta \mathrm{F}_{\text {inh }}$ is the ionomycininduced activity in the presence of inhibitor. Triplicate measurements were performed for each sample.

\section{FACS Analysis of Apoptotic Cells}

Cells were treated with $2 \mu \mathrm{m}$ ionomycin for $3 \mathrm{~h}$ at $37^{\circ} \mathrm{C}$. Before being counted and sorted by FACS, annexin V-fluorescein and propidium iodide were added as described (Gil-Parrado et al., 2002). Phosphatidylserine externalization (\%) represents the percentage of cells positive for phosphatidylserine externalization and negative for propidium iodide uptake, related to the total amount of cells. Inhibition of phosphatidylserine externalization was measured after pre-incubation of the cells for $1 \mathrm{~h}$ with different concentrations of the inhibitors $\mathrm{CP} 1 \mathrm{~B}$ and PCP1B, followed by incubation with ionomycin and FACS counting. All experiments were performed in triplicate.

\section{Acknowledgments}

We are grateful to Frauke Melchior, Victor Magdolen and Eberhard Spiess for facilities to perform protease activity measure- 
ments in living cells and to use FACS equipment and an epifluorescence microscope. Rita Zauner, Dominique Helmeke, Barbara Meisel and Reinhard Mentele are acknowledged for their excellent technical assistance. This work was supported by the Sonderforschungsbereich 469 of the Ludwig-Maximilians-Universität München (grants A2 to L.M. and A6 to W.M.)

\section{References}

Arthur, J. S., Elce, J. S., Hegadorn, C., Williams, K., and Greer, P. A. (2000). Disruption of the murine calpain small subunit gene, Capn4: calpain is essential for embryonic development but not for cell growth and division. Mol. Cell. Biol. 20, 44744481.

Bepler, G., Koehler, A., Kiefer, P., Havemann, K., Beisenherz, K., Jaques, G., Gropp, C., and Haeder, M. (1988). Characterization of the state of differentiation of six newly established human non-small-cell lung cancer cell lines. Differentiation 37, $158-171$.

Bernatowicz, M. S., Matsueda, R., and Matsueda, G. R. (1986). Preparation of Boc-[S-(3-nitro-2-pyridinesulfenyl)]-cysteine and its use for unsymmetrical disulfide bond formation. Int. J. Pept. Protein Res. 28, 107-112.

Blomgren, K., Zhu, C., Wang, X., Karlsson, J. O., Leverin, A. L., Bahr, B. A., Mallard, C., and Hagberg, H. (2001). Synergistic activation of caspase-3 by m-calpain after neonatal hypoxiaischemia: a mechanism of 'pathological apoptosis'? J. Biol. Chem. 276, 10191-10198.

Bordone, L., and Campbell, C. (2002). DNA ligase III is degraded by calpain during cell death induced by DNA damaging agents. J. Biol. Chem. 277, 26673-26680.

Carragher, N. O., Westhoff, M. A., Riley, D., Potter, D. A., Dutt, P., Elce, J. S., Greer, P. A., and Frame, M. C. (2002). v-Src-induced modulation of the calpain-calpastatin proteolytic system regulates transformation. Mol. Cell Biol. 22, 257-269.

Chen, M., Won, D. J., Krajewski, S., and Gottlieb, R. A. (2002). Calpain and mitochondria in ischemia/reperfusion injury. J. Biol. Chem. 277, 29181-29186.

Croall, D. E., and McGrody, K. S. (1994). Domain structure of calpain: mapping the binding site for calpastatin. Biochemistry 33, 13223-13230.

Croce, K., Flaumenhaft, R., Rivers, M., Furie, B., Furie, B. C., Herman, I. M., and Potter, D. A. (1999). Inhibition of calpain blocks platelet secretion, aggregation, and spreading. J. Biol. Chem. 274, 36321-36327.

Derossi, D., Chassaing, G., and Prochiantz, A. (1998). Trojan peptides: the penetratin system for intracellular delivery. Trends Cell Biol. 8, 84-87.

Donkor, I. O. (2000). A survey of calpain inhibitors. Curr. Med. Chem. 7, 1171-1188.

Eto, A., Akita, Y., Saido, T. C., Suzuki, K., and Kawashima, S. (1995). The role of the calpain-calpastatin system in thyrotropin-releasing hormone-induced selective down-regulation of a protein kinase $\mathrm{C}$ isozyme, $\mathrm{nPKC}$ epsilon, in rat pituitary GH4C1 cells. J. Biol. Chem. 270, 25115-25120.

Fischer, P. M., Krausz, E., and Lane, D. P. (2001). Cellular delivery of impermeable effector molecules in the form of conjugates with peptides capable of mediating membrane translocation. Bioconjug. Chem. 12, 825-841.

Gabrijelcic-Geiger, D., Mentele, R., Meisel, B., Hinz, H., AssfalgMachleidt, I., Machleidt, W., Möller, A., and Auerswald, E. A. (2001). Human $\mu$-calpain: simple isolation from erythrocytes and characterization of autolysis fragments. Biol. Chem. 382, $1733-1737$.

Gil-Parrado, S., Fernandez-Montalvan, A., Assfalg-Machleidt, I.,
Popp, O., Bestvater, F., Holloschi, A., Knoch, T. A., Auerswald, E. A., Welsh, K., Reed, J. C., Fritz, H., Fuentes-Prior, P., Spiess, E., Salvesen, G. S., and Machleidt, W. (2002). Ionomycin-activated calpain triggers apoptosis: A probable role for Bcl-2 family members. J. Biol. Chem. 277, 27217-27226.

Glading, A., Lauffenburger, D. A., and Wells, A. (2002). Cutting to the chase: calpain proteases in cell motility. Trends Cell Biol. $12,46-54$.

Hällbrink, M., Floren, A., Elmquist, A., Pooga, M., Bartfai, T., and Langel, U. (2001). Cargo delivery kinetics of cell-penetrating peptides. Biochim. Biophys. Acta 1515, 101-109.

Hernandez, A. A., and Roush, W. R. (2002). Recent advances in the synthesis, design and selection of cysteine protease inhibitors. Curr. Opin. Chem. Biol. 6, 459-465.

Hiwasa, T., Nakata, M., Ohno, S., Maki, M., Suzuki, K., and Takiguchi, M. (2002). Regulation of transformed state by calpastatin via PKCepsilon in NIH3T3 mouse fibroblasts. Biochem. Biophys. Res. Commun. 290, 510-517.

Huang, Y., and Wang, K. K. (2001). The calpain family and human disease. Trends Mol. Med. 7, 355-362.

Kawasaki, H., Emori, Y., Imajoh-Ohmi, S., Minami, Y., and Suzuki, K. (1989). Identification and characterization of inhibitory sequences in four repeating domains of the endogenous inhibitor for calcium-dependent protease. J. Biochem. (Tokyo) 106, 274-281.

Kusakawa, G., Saito, T., Onuki, R., Ishiguro, K., Kishimoto, T., and Hisanaga, S. (2000). Calpain-dependent proteolytic cleavage of the p35 cyclin-dependent kinase 5 activator to p25. J. Biol. Chem. 275, 17166-17172.

Lindgren, M., Gallet, X., Soomets, U., Hallbrink, M., Brakenhielm, E., Pooga, M., Brasseur, R., and Langel, U. (2000a). Translocation properties of novel cell penetrating transportan and penetratin analogues. Bioconjug. Chem. 11, 619-626.

Lindgren, M., Hallbrink, M., Prochiantz, A., and Langel, U. (2000b). Cell-penetrating peptides. Trends Pharmacol. Sci. 21, 99-103.

Lu, T., Xu, Y., Mericle, M. T., and Mellgren, R. L. (2002). Participation of the conventional calpains in apoptosis. Biochim. Biophys. Acta 1590, 16-26.

Machleidt, W., Assfalg-Machleidt, I. and Auerswald, E.A. (1993). Kinetics and molecular mechanism of inhibition of cysteine proteinases by their protein inhibitors. In: Innovations in Proteases and their Inhibitors, F.X. Aviles, ed. (Berlin, Germany: Walter de Gruyter), pp. 179-196.

Maki, M., Takano, E., Osawa, T., Ooi, T., Murachi, T., and Hatanaka, M. (1988). Analysis of structure-function relationship of pig calpastatin by expression of mutated cDNAs in Escherichia coli. J. Biol. Chem. 263, 10254-10261.

Maki, M., Bagci, H., Hamaguchi, K., Ueda, M., Murachi, T., and Hatanaka, M. (1989). Inhibition of calpain by a synthetic oligopeptide corresponding to an exon of the human calpastatin gene. J. Biol. Chem. 264, 18866-18869.

Moldoveanu, T., Hosfield, C. M., Lim, D., Elce, J. S., Jia, Z., and Davies, P. L. (2002). A Ca ${ }^{2+}$ switch aligns the active site of calpain. Cell 108, 649-660.

Morrison, J. F. (1982). The slow-binding and slow, tight-binding inhibition of enzyme- catalyzed reactions. Trends Biochem. Sci. 7, 102-105.

Naito, M., Nagashima, K., Mashima, T., and Tsuruo, T. (1997). Phosphatidylserine externalization is a downstream event of interleukin-1 $\beta$-converting enzyme family protease activation during apoptosis. Blood 89, 2060-2066.

Rutledge, T. W., and Whiteheart, S. W. (2002). SNAP-23 is a target for calpain cleavage inactivated platelets. J. Biol. Chem., in press (July 16, 2002) 10.1074/jbc.M204526200.

Sasaki, T., Kishi, M., Saito, M., Tanaka, T., Higuchi, N., Komina- 
mi, E., Katunuma, N., and Murachi, T. (1990). Inhibitory effect of di- and tripeptidyl aldehydes on calpains and cathepsins. J. Enzyme Inhib. 3, 195-201.

Sato, K., and Kawashima, S. (2001). Calpain function in the modulation of signal transduction molecules. Biol. Chem. 382, 743-751.

Schaschke, N., Musiol, H. J., Assfalg-Machleidt, I., Machleidt, W., Rudolph-Bohner, S., and Moroder, L. (1996). Cyclodextrins as templates for the presentation of protease inhibitors. FEBS Lett. 391, 297-301.

Schaschke, N., Deluca, D., Assfalg-Machleidt, I., Hohneke, C., Sommerhoff, C. P., and Machleidt, W. (2002). Epoxysuccinyl peptide-derived cathepsin B inhibitors: modulating membrane permeability by conjugation with the C-terminal heptapeptide segment of penetratin. Biol. Chem. 383, 849-852.

Schoenwaelder, S. M., and Burridge, K. (1999). Evidence for a calpeptin-sensitive protein-tyrosine phosphatase upstream of the small GTPase Rho. A novel role for the calpain inhibitor calpeptin in the inhibition of protein-tyrosine phosphatases. J. Biol. Chem. 274, 14359-14367.

Shiraishi, S., Shibuya, I., Uezono, Y., Yokoo, H., Toyohira, Y., Yamamoto, R., Yanagita, T., Kobayashi, H., and Wada, A. (2001). Heterogeneous increases of cytoplasmic calcium: distinct effects on down-regulation of cell surface sodium channels and sodium channel subunit mRNA levels. Br. J. Pharmacol. 132, $1455-1466$.

Sorimachi, H., and Suzuki, K. (2001). The structure of calpain. J. Biochem. (Tokyo) 129, 653-664.

Squier, M. K., Sehnert, A. J., Sellins, K. S., Malkinson, A. M., Takano, E., and Cohen, J. J. (1999). Calpain and calpastatin regulate neutrophil apoptosis. J. Cell Physiol. 178, 311-319.

Stein, R. L., Melandri, F., and Dick, L. (1996). Kinetic characterization of the chymotryptic activity of the $20 \mathrm{~S}$ proteasome. Biochemistry 35, 3899-3908.

Takano, E., Ma, H., Yang, H. Q., Maki, M., and Hatanaka, M. (1995). Preference of calcium-dependent interactions between calmodulin-like domains of calpain and calpastatin subdomains. FEBS Lett. 362, 93-97.

Uemori, T., Shimojo, T., Asada, K., Asano, T., Kimizuka, F., Kato, I., Maki, M., Hatanaka, M., Murachi, T., Hanzawa, H., and et al. (1990). Characterization of a functional domain of human cal- pastatin. Biochem. Biophys. Res. Commun. 166, 14851493.

Van Den Bosch, L., Van Damme, P., Vleminckx, V., Van Houtte, E., Lemmens, G., Missiaen, L., Callewaert, G., and Robberecht, W. (2002). An $\alpha$-mercaptoacrylic acid derivative (PD150606) inhibits selective motor neuron death via inhibition of kainate-induced $\mathrm{Ca}^{2+}$ influx and not via calpain inhibition. Neuropharmacology 42, 706-713.

Vanderklish, P. W., and Bahr, B. A. (2000). The pathogenic activation of calpain: a marker and mediator of cellular toxicity and disease states. Int. J. Exp. Pathol. 81, 323-339.

Waizenegger, T., Fischer, R., and Brock, R. (2002). Intracellular concentration measurements in adherent cells: a comparison of import efficiencies of cell-permeable peptides. Biol. Chem. 383, 291-299.

Wang, K. K., Nath, R., Posner, A., Raser, K. J., Buroker-Kilgore, M., Hajimohammadreza, I., Probert, A. W., Jr., Marcoux, F. W., Ye, Q., Takano, E. et al. (1996). An $\alpha$-mercaptoacrylic acid derivative is a selective nonpeptide cell-permeable calpain inhibitor and is neuroprotective. Proc. Natl. Acad. Sci. USA 93, $6687-6692$.

Wang, K. K., and Yuen, P. W. (1997). Development and therapeutic potential of calpain inhibitors. Adv. Pharmacol. 37, $117-152$

Wang, K. K. (2000). Calpain and caspase: can you tell the difference? Trends Neurosci. 23, 20-26.

Yajima, Y., and Kawashima, S. (2002). Calpain function in the differentiation of mesenchymal stem cells. Biol. Chem. 383, 757-764.

Yamashima, T. (2000). Implication of cysteine proteases calpain, cathepsin and caspase in ischemic neuronal death of primates. Prog. Neurobiol. 62, 273-295.

Yamazaki, M., Ishidoh, K., Suga, Y., Saido, T. C., Kawashima, S., Suzuki, K., Kominami, E., and Ogawa, H. (1997a). Cytoplasmic processing of human profilaggrin by active $\mu$-calpain. Biochem. Biophys. Res. Commun. 235, 652-656.

Yamazaki, T., Haass, C., Saido, T. C., Omura, S., and Ihara, Y. (1997b). Specific increase in amyloid $\beta$-protein 42 secretion ratio by calpain inhibition. Biochemistry $36,8377-8383$.

Receievd September 27, 2002; accepted November 8, 2002 